\title{
Impact factor and the IUJ
}

\author{
Rebecca Rogers ${ }^{1}$
}

Received: 3 August 2021 / Accepted: 4 August 2021 / Published online: 10 September 2021

(C) The International Urogynecological Association 2021

One of this year's highlights is the success of the International Urogynecology Journal. As you know, our journal publishes more manuscripts on pelvic floor disorders than any other journal, and our readership spans the globe. During COVID, like many other journals, we saw a large surge (no pun intended) of journal submissions. In recent years, the IUJ has received between 700 and 800 submissions annually and accepted approximately 300 to 330 submissions each year. Last year, we received 1171 submissions and accepted 448 manuscripts, a $35 \%$ increase. As the depths of the pandemic have eased, the number of submissions has declined to a more manageable level.

How do you measure the worth of a journal? Our journal's mission is to serve the urogynecology community, including both our readers and researchers. I often receive comments from our readers that the enjoy the journal and look forward to reading it when it comes out. Our researchers value the journal because of the short turnaround time from submission to decision and the large readership who will see their work.

One of the ways that the "value" of a journal is measured is by the impact factor. Traditionally, the impact factor is a measure of how many citations articles in the journal receive, divided by how many articles are published. Despite more submissions (and more acceptances), the IUJ's impact factor increased this year to 2.894 from 2.071. This occurred for a few reasons. Not all articles "count" in the denominator-
"Images in Urogynecology" is an example of a feature that does not go into the denominator of our impact factor. In addition, until this year, citations were only counted if the article had been published in paper; citation of online articles did not count. To better serve our readership, the IUJ has a short turnaround time to publish articles online, which often appear months before the printed version. The new way of calculating the impact factor better reflects the utility of our publications to the research community, by "counting" citations that occur while the article is online but not in print. Even more important than the impact factor is the change of our rank among like publications. Among the three journals that are closest to us in quality, scope and purpose, the IUJ ranks above Neurourology and Urodynamics and Female Pelvic Medicine and Reconstructive Surgery.

Steve and I would like to personally thank all of those who have made the success of the journal possible. Our editors, who managed the tremendous number of submissions we have had over the past year and a half; our reviewers, who help us choose the best science to publish; our authors, who submit their work; and our readers, who use the science to provide up-to-date care to their patients.

Publisher's note Springer Nature remains neutral with regard to jurisdictional claims in published maps and institutional affiliations.
Rebecca Rogers

rogersr2@amc.edu

1 Albany Medical College, Albany, NY, USA 